

Cite this: RSC Adv., 2017, 7, 10865

Received 15th November 2016 Accepted 4th February 2017

DOI: $10.1039 / c 6 r a 26826 a$

rsc.li/rsc-advances

\section{Electrochemiluminescent chemodosimetric probes for sulfide based on cyclometalated Ir(III) complexes $\uparrow$}

\author{
Seo-Yeon Kim, Hoon Jun Kim and Jong-In Hong*
}

We developed two electrochemiluminescent probes $(1,2)$ for sulfide $\left(S^{2-}\right)$, based on cyclometalated $\operatorname{Ir}($ III) complexes. Addition of sulfide anions greatly increased the ECL signal of probes by cleaving a PET quencher moiety from probe ligands. Probe 2 showed a high turn-on ratio of ECL and good selectivity for sulfide anions over various anions and biothiols.
Hydrogen sulfide $\left(\mathrm{H}_{2} \mathrm{~S}\right)$, a well-known toxic gas, has recently been recognized as an important gaseous signalling molecule. ${ }^{1,2} \mathrm{H}_{2} \mathrm{~S}$ is generated endogenously from L-cysteine by several enzymes such as cystathionine $\gamma$-lyase (CSE), ${ }^{3}$ cystathionine $\beta$-synthase (CBS), ${ }^{4}$ and 3-mercaptopyruvate sulfur transferase (3-MST). ${ }^{5}$ As a gasotransmitter, $\mathrm{H}_{2} \mathrm{~S}$ regulates various biological processes in the cardiovascular, ${ }^{6}$ central nervous, ${ }^{7}$ immune, ${ }^{8}$ and gastrointestinal ${ }^{9}$ systems. In blood plasma, 10-100 $\mu \mathrm{M}$ of sulfide is considered the normal level. ${ }^{10,11}$ However, an abnormal level of $\mathrm{H}_{2} \mathrm{~S}$ is associated with some diseases, including Alzheimer's disease, ${ }^{12}$ Down's syndrome, diabetes ${ }^{13}$ and liver cirrhosis. ${ }^{14}$ Therefore, simple methods for selective detection of $\mathrm{H}_{2} \mathrm{~S}$ are required in order to diagnose various diseases that increase the plasma $\mathrm{H}_{2} \mathrm{~S}$ concentration to abnormal levels.

So far, various approaches have been studied for the detection of $\mathrm{H}_{2} \mathrm{~S}$, such as electrochemical analysis, ${ }^{15}$ gas chromatography, ${ }^{16}$ and colorimetric ${ }^{17}$ and fluorescent ${ }^{18}$ assays. In particular, a large number of fluorescent chemodosimeters for $\mathrm{H}_{2} \mathrm{~S}$ were developed based on the strong reducing ${ }^{19,20}$ or nucleophilic ${ }^{21,22}$ properties of sulfide anions. However, fluorescent assays cannot be used for point-of-care (POC) detection due to the requirement of an additional optical source and bulky equipment.

Electrochemiluminescence (ECL) is a light-emitting process caused by the electron-transfer reaction between electrochemically generated radical species at the electrodes. ${ }^{23}$ In comparison with conventional fluorescent methods, the ECL method has many advantages, including no background optical signal, high sensitivity and no need of extra light sources, providing simple and miniaturized sensing tools. ${ }^{23-25}$ These features afford strong benefits in the development of POC detection sensors. ECL luminophores were developed using various phosphorescent

Department of Chemistry, Seoul National University, 1 Gwanak-ro, Gwanak-gu, Seoul 151-747, Korea.E-mail: jihong@snu.ac.kr

$\uparrow$ Electronic supplementary information (ESI) available: Experimental details and additional spectroscopic data. See DOI: 10.1039/c6ra26826a heavy-metal complexes such as $\mathrm{Ru}(\mathrm{II}),{ }^{26} \mathrm{Os}(\mathrm{II}),{ }^{27} \mathrm{Eu}(\mathrm{III}),{ }^{28} \mathrm{Re}(\mathrm{I}),{ }^{29}$ $\mathrm{Pt}(\mathrm{II}),{ }^{30}$ and $\operatorname{Ir}(\mathrm{III}) .{ }^{31-33}$ Among them, $\operatorname{Ir}(\mathrm{III})$ complexes have attracted increasing attention because they exhibit high luminescence efficiency, good electrochemical stability, and easy tunability of the luminescent colour by modulating the substitution of ligands. ${ }^{31-33}$

Herein, we designed two ECL chemodosimetric probes for the sulfide anion based on $\operatorname{Ir}($ III) complexes (Scheme 1). We selected $(\text { piq })_{2} \operatorname{Ir}($ pic $)(p i q=1$-phenylisoquinoline, pic $=$ picolinate) as a luminophore, ${ }^{34}$ and the dinitrophenyl (DNP) group as a photo-induced electron transfer (PET) quencher ${ }^{35}$ and a reaction site,$^{35-37}$ providing bright emission after the nucleophilic aromatic substitution $\left(\mathrm{S}_{\mathrm{N}} \mathrm{Ar}\right)$ by the sulfide anion. Probe $\mathbf{1}$ has a DNP group on the ancillary ligand, while probe 2 has an additional quencher group on the main ligands that would

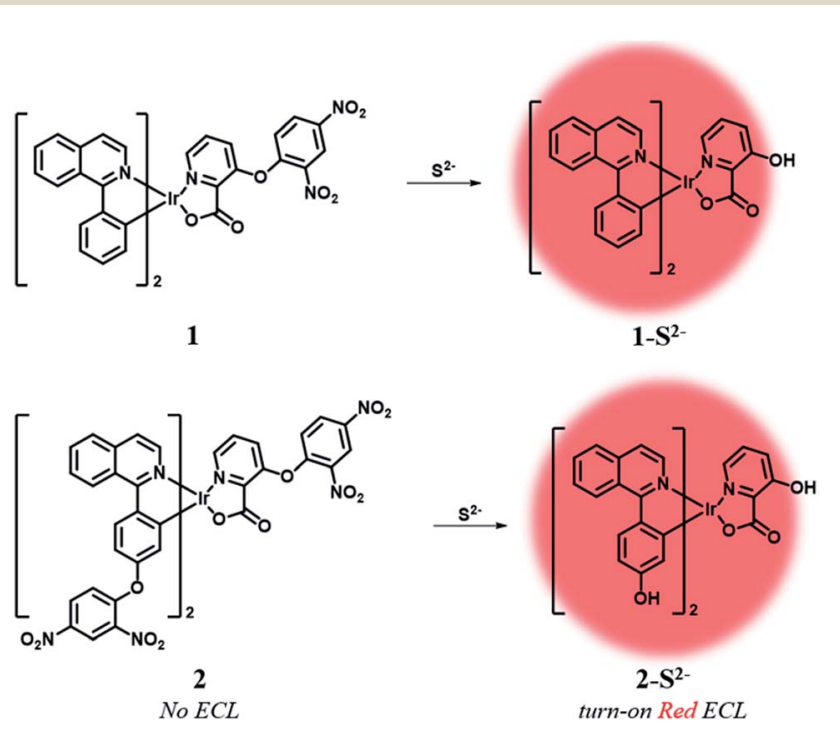

Scheme 1 Electrogenerated chemiluminescent sensing mechanism of probes 1 and 2 . 
further reduce the phosphorescent intensity of the probe itself and thus produce a high turn-on ratio in response to sulfide anions. The reaction products of probes 1 and $\mathbf{2}$ were confirmed by MALDI-TOF mass spectra (Fig. S1 and S2 $\dagger$ ). Synthetic procedures of probes $\mathbf{1}$ and $\mathbf{2}$ are described in the ESI (Schemes $\mathrm{S} 1$ and $\mathrm{S} 2 \dagger)$.

Initially, we examined the phosphorescence spectra of probes 1 and 2. As shown in Fig. 1a, the phosphorescence intensity of 1 gradually increased at $606 \mathrm{~nm}\left(\lambda_{\mathrm{ex}}=460 \mathrm{~nm}\right)$ until 10 equiv. of sulfide anion $(100 \mu \mathrm{M})$ was added. The phosphorescence intensity of 2 increased more dramatically than $\mathbf{1}$ at $601 \mathrm{~nm}$ (Fig. 1b). Probe 2 required a larger amount of sulfide anion (150 $\mu \mathrm{M}, 15$ equiv.) than 1 for saturation because the former has more reaction sites for sulfide. The estimated limit of detection (LOD) was calculated to be $1.9 \mu \mathrm{M}$ for 1 and $0.2 \mu \mathrm{M}$ for 2 (signal-to-noise $(\mathrm{S} / \mathrm{N})$ ratio $=3$ ). Then, we compared the phosphorescence turn-on ratios of $\mathbf{1}$ and 2 in the presence of $100 \mu \mathrm{M}$ of sulfide anion (Fig. 1c). The turn-on ratio of 2 was greater than 1, as we expected. UV-vis absorption spectra were also investigated (Fig. 1d). In the presence of sulfide (10 equiv.), the absorption peak around $457 \mathrm{~nm}$ increased significantly. Probe 2 solution showed the corresponding colour change from colourless to yellow, enabling colorimetric detection through the naked eye.

Density functional theory (DFT) calculations supported the PET sensing mechanism of the probes (Fig. S3†). The HOMOs of $\mathbf{1}$ and $\mathbf{2}$ were mainly localized on the Ir(III) centre and phenyl ring of piq and the LUMO is localized on the DNP, whereas the LUMO of Ir(III) complexes is generally localized on the isoquinoline of the main ligands. Hence, we expected that probes 1 and 2 were able to show an "off-on" emission signal in response to sulfide through the PET modulation. We also conducted
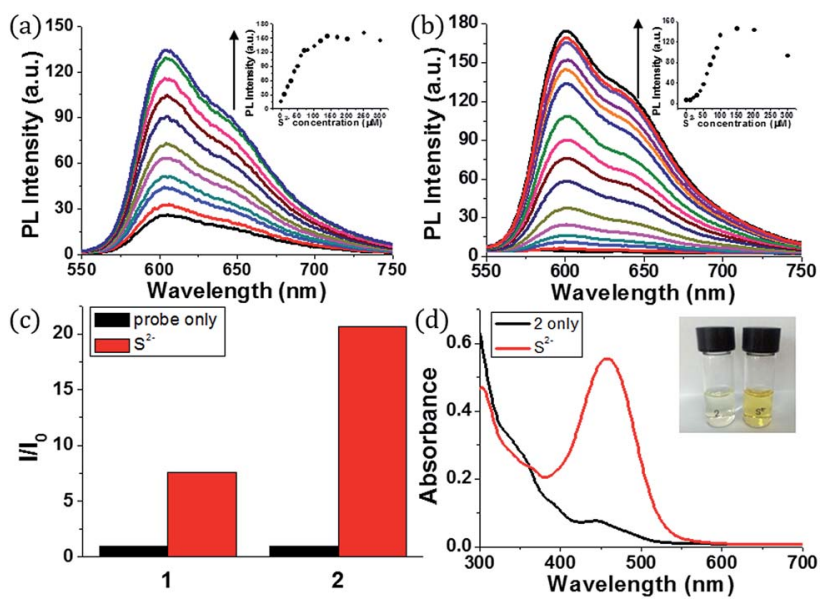

Fig. 1 (a) Phosphorescent emission spectra of $1(10 \mu \mathrm{M})$ in the presence of $0-100 \mu \mathrm{M}$ of sulfide in $\mathrm{CH}_{3} \mathrm{CN}$ (inset: changes in phosphorescence intensity of 1 at $606 \mathrm{~nm}$ upon the addition of sulfide) (b) phosphorescent emission spectra of $2(10 \mu \mathrm{M})$ in the presence of $0-$ $150 \mu \mathrm{M}$ of sulfide in $\mathrm{CH}_{3} \mathrm{CN}$ (inset: changes in phosphorescent intensity of 2 upon the addition of sulfide) (c) turn-on ratio of 1 and 2 in the absence (black bar) and presence (red bar) of $100 \mu \mathrm{M}$ sulfide in $\mathrm{CH}_{3} \mathrm{CN}(\mathrm{d}) \mathrm{UV}$-vis absorption of $2(10 \mu \mathrm{M})$ before and after addition of sulfide $(100 \mu \mathrm{M})$ in $\mathrm{CH}_{3} \mathrm{CN}$. cyclic voltammetry (CV) measurements and compared the HOMO/LUMO energy levels of luminophores $\left(1-\mathrm{S}^{2-}\right.$ and $\left.2-\mathrm{S}^{2-}\right)$ with the LUMO of a quencher (1-chloro-2,4-dinitrobenzene) to confirm the PET mechanism experimentally (Fig. 2). As expected, the LUMO $(-4.36 \mathrm{eV})$ of the quencher is located between the HOMO $(-5.35 \mathrm{eV})$ and LUMO $(-3.08 \mathrm{eV})$ of $1-\mathrm{S}^{2-}$ as well as the HOMO $(-5.19 \mathrm{eV})$ and LUMO $(-2.87 \mathrm{eV})$ of $2-\mathrm{S}^{2-}$. Therefore, the phosphorescence signal of the probes was quenched by the PET process before the cleavage of the DNP moiety from Ir(III) complexes upon the addition of sulfide.

The ECL measurements were performed during the CV process. Probe 1 itself showed the initial ECL intensity at around $1.4 \mathrm{~V}$, but further increase in the ECL intensity of 1 was observed in the presence of sulfide (Fig. 3a). A titration curve of

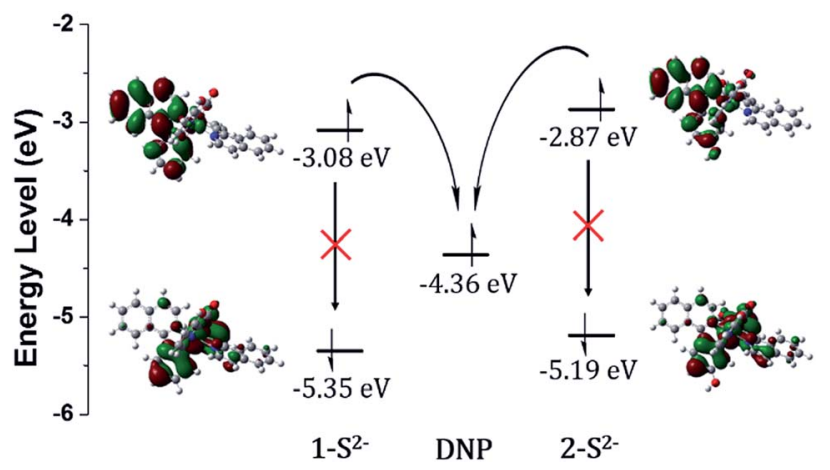

Fig. $2 \mathrm{HOMO/LUMO}$ energy levels calculated from CV measurements and electronic distributions of $1-\mathrm{S}^{2-}$ and $2-\mathrm{S}^{2-}$ and photo-induced electron transfer pathway.

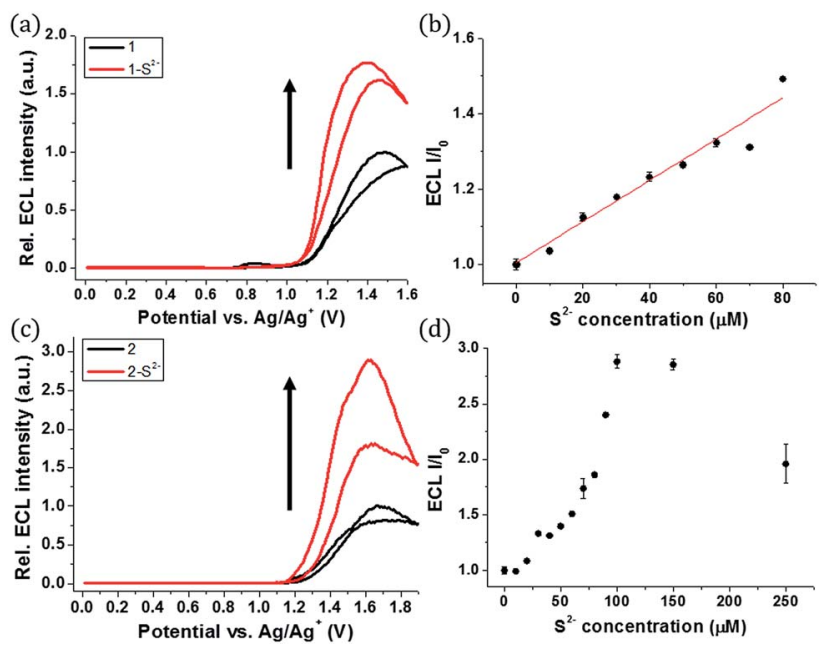

Fig. 3 (a) $E C L$ intensity of $1(10 \mu M)$ upon the addition of sulfide ( 80 $\mu \mathrm{M}$ ) in $\mathrm{CH}_{3} \mathrm{CN}$ (25 mM TPA, and $0.1 \mathrm{M} \mathrm{TBAPF}_{6}$ as the supporting electrolyte) (b) $E C L$ titration curve of $1(10 \mu \mathrm{M})$ upon the addition of sulfide in $\mathrm{CH}_{3} \mathrm{CN}$ (10 mM TPA, and 0.1 M TBAPF 6 as the supporting electrolyte) (c) ECL intensity of $2(10 \mu \mathrm{M})$ upon the addition of sulfide $(150 \mu \mathrm{M})$ in $\mathrm{CH}_{3} \mathrm{CN}$ (25 mM TPA, and 0.1 M TBAPF 6 as the supporting electrolyte) (d) $\mathrm{ECL}$ titration curve of $2(10 \mu \mathrm{M})$ upon the addition of sulfide in $\mathrm{CH}_{3} \mathrm{CN}$ (10 mM TPA, 0.1 M TBAPF $\mathrm{M}_{6}$ as the supporting electrolyte) (the potential is swept at a Pt disk electrode (diameter: $2 \mathrm{~mm}$ ) vs. $\mathrm{Ag} / \mathrm{Ag}^{+}$, scan rate: $0.1 \mathrm{~V} \mathrm{~s}^{-1}$ ). 
1 was obtained against various concentrations of the sulfide anion (Fig. 3b). A linear relationship between the ECL intensity and the sulfide concentration was observed from 0 to $80 \mu \mathrm{M}$ of sulfide. The estimated LOD was calculated to be $27 \mathrm{nM}$, significantly lower than the LOD of phosphorescence. Hence, 1 can be used as a highly sensitive ECL sensor to detect abnormal levels of $\mathrm{S}^{2-}$.

A similar turn-on ECL of 2 was observed in the presence of sulfide (Fig. 3c). Probe 2 showed 3-fold enhancement of the ECL intensity at around $1.6 \mathrm{~V}$ in the presence of 15 equiv. of sulfide $(150 \mu \mathrm{M})$. The emission signal increased greatly when the sulfide concentration was in the range of $0-100 \mu \mathrm{M}$ (Fig. 3d). Although the ECL turn-on ratio of 2 was greater than that of $\mathbf{1}$, the absolute ECL intensity of 2 was low even after saturation with sulfide (Fig. S4†). The maximum signal of 2 was only $5.7 \%$ of 1 in the presence of sulfide ( $80 \mu \mathrm{M}, 8$ equiv.) (Table S1†). The low ECL intensity of 2 caused low sensitivity toward the sulfide anion, and the estimated LOD of 2 was calculated to be $0.3 \mu \mathrm{M}$, which is relatively high compared to that of $\mathbf{1}$ (Fig. S5 $\dagger$ ).

The low ECL intensity of 2 can be explained by the CV measurements (Fig. 4). We compared the HOMO/LUMO energy levels of 1-S ${ }^{2-}$ and $2-\mathrm{S}^{2-}$ calculated from $\mathrm{CV}$ measurements with the HOMO of tri- $n$-propylamine (TPA). One of the conditions for the efficient ECL emission is that the HOMO of the emitter should be lower than that of TPA for an efficient generation of $\mathrm{TPA}^{+} \cdot{ }^{38}$ The HOMO energy level of $1-\mathrm{S}^{2-}(-5.35 \mathrm{eV})$ is relatively well matched with that of TPA $(-5.38 \mathrm{eV})$, so that 1 can emit a strong ECL in response to the sulfide anion through the relatively smooth electron transfer from TPA HOMO to 1-S $\mathrm{S}^{2-}$ HOMO. In contrast, the HOMO energy level of $2-\mathrm{S}^{2-}(-5.19 \mathrm{eV})$ is quite higher than that of TPA because the hydroxyl groups on the main ligands destabilized the HOMO level. Thus, the electron transfer from TPA to $2-\mathrm{S}^{2-}$ hardly occurred, causing a weak ECL emission. The CV studies rationalized the low ECL intensity of 2 . Furthermore, the energy level of the TPA radical is higher than that of the LUMO of $\left(1-\mathrm{S}^{2-}\right)^{+\bullet}$ or $\left(2-\mathrm{S}^{2-}\right)^{+\bullet}$, so that the excited state of $\left(1-\mathrm{S}^{2-}\right)^{+\cdot}$ or $\left(2-\mathrm{S}^{2-}\right)^{+}$can be easily formed to generate the ECL. ${ }^{39}$

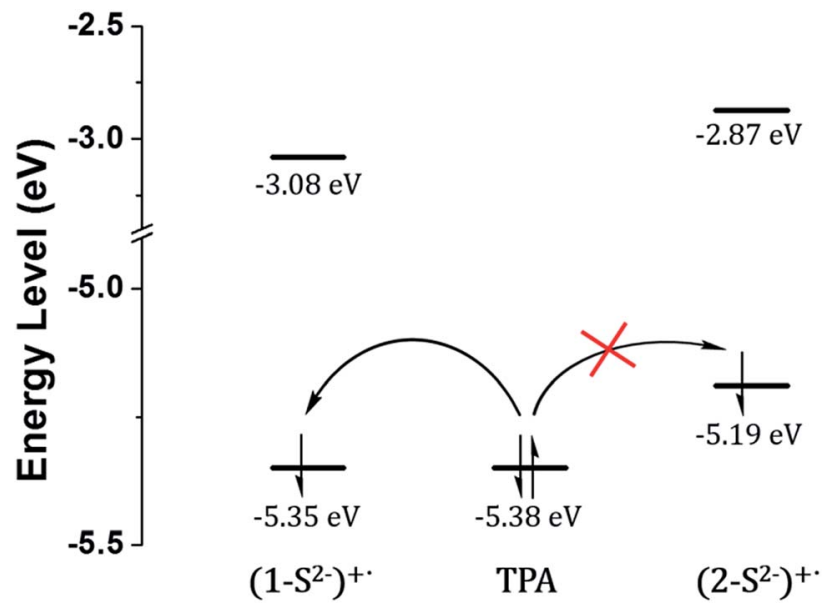

Fig. $4 \mathrm{HOMO/LUMO}$ energy levels calculated from CV measurements and generation of $\mathrm{TPA}^{+} \cdot$ through the catalytic pathway.



Fig. $5 \mathrm{ECL}$ responses of $2(10 \mu \mathrm{M})$ in the presence of various analytes $(100 \mu \mathrm{M})$ in $\mathrm{CH}_{3} \mathrm{CN}$. (25 mM TPA, and 0.1 $\mathrm{M} \mathrm{TBAPF}_{6}$ as the supporting electrolyte) (a) probe only, (b) $\mathrm{F}^{-}$, (c) $\mathrm{Cl}^{-}$, (d) $\mathrm{Br}^{-}$, (e) $\mathrm{I}^{-}$, (f) $\mathrm{HCO}_{3}^{-}$, (g) $\mathrm{CO}_{3}^{2-}$, (h) $\mathrm{C}_{2} \mathrm{O}_{4}{ }^{2-}$, (i) $\mathrm{SO}_{4}{ }^{2-}$, (j) $\mathrm{NO}_{3}^{-}$, (k) $\mathrm{N}_{3}^{-}$, (l) $\mathrm{AcO}^{-}$, (m) $\mathrm{SCN}^{-}$, (n) $\mathrm{CN}^{-}$, (o) Cys, (p) Hcy, (q) GSH, (r) $\mathrm{S}^{2-}$.

Further, we carried out additional experiments with $\mathrm{Ru}(\mathrm{bpy})_{3}{ }^{2+}$, the most frequently used ECL luminophore, to confirm the effect of remaining sulfide ions on the ECL signal in solution (Fig. S6 $\dagger$ ). We confirmed that almost no ECL changes were observed in the presence of excess sulfide ( $100 \mu \mathrm{M}, 10$ equiv.), when compared to the ECL intensity of $\mathrm{Ru}(\mathrm{bpy})_{3}{ }^{2+}$ in the absence of sulfide ions. These data could prove that remaining excess sulfide ions in solution have only a little effect on the change of ECL intensities.

The selectivity of 1 and 2 was tested by adding $100 \mu \mathrm{M}$ of each anion to $10 \mu \mathrm{M}$ of probe 2 (Fig. 5 and S7-S9 $\dagger$ ). Only the sulfide anion induced a significant increase in the ECL intensity, whereas almost no ECL changes were observed upon the addition of other anions, including $\mathrm{F}^{-}, \mathrm{Cl}^{-}, \mathrm{Br}^{-}, \mathrm{I}^{-}, \mathrm{HCO}_{3}{ }^{-}$, $\mathrm{CO}_{3}{ }^{2-}, \mathrm{C}_{2} \mathrm{O}_{4}{ }^{2-}, \mathrm{SO}_{4}{ }^{2-}, \mathrm{NO}_{3}{ }^{-}, \mathrm{N}_{3}{ }^{-}, \mathrm{AcO}^{-}$, and $\mathrm{SCN}^{-}$. In particular, $\mathrm{CN}^{-}$and biothiols such as cysteine, homocysteine, and glutathione, which are difficult to be distinguished from sulfide, could not increase the emission intensity. These results suggest that probe 2 is a highly selective probe for sulfide $\left(\mathrm{S}^{2-}\right)$ over other analytes and can be used for biological applications based on ECL analysis.

\section{Conclusions}

We designed two "off-on" chemodosimetric ECL probes for sulfide $\left(\mathrm{S}^{2-}\right)$, based on cyclometalated Ir(III) complexes. In the presence of sulfide anions, the ECL intensity of probe 2 increased greatly due to the blocking of the PET quenching process. Furthermore, the probe showed a high turn-on ratio with sulfide only. We expect that our rational sensing approach will pave the way for the development of various ECL-based sensing tools for small biomolecules.

\section{Acknowledgements}

This work was supported by the National Research Foundation (Grant No. 2015R1A2A1A15055347) funded by the MSIP. 


\section{Notes and references}

1 M. M. Gadalla and S. H. Snyder, J. Neurochem., 2010, 113, 1426.

2 O. Kabil and R. Banerjee, J. Biol. Chem., 2010, 285, 2190321907.

3 N. Sen, B. D. Paul, M. M. Gadalla, A. K. Mustafa, T. Sen, R. Xu, S. Kim and S. H. Snyder, Mol. Cell, 2012, 45, 13-24.

4 S. Singh, D. Padovani, R. A. Leslie, T. Chiku and R. Banerjee, J. Biol. Chem., 2009, 284, 22457-22466.

5 M. T. Norihiro Shibuya, M. Yoshida, Y. Ogasawara, T. Togawa, K. Ishii and H. Kimura, Antioxid. Redox Signaling, 2009, 11, 703-714.

6 J. W. Calvert, S. Jha, S. Gundewar, J. W. Elrod, A. Ramachandran, C. B. Pattillo, C. G. Kevil and D. J. Lefer, Circ. Res., 2009, 105, 365-374.

7 K. Abe and H. Kimura, J. Neurosci., 1996, 16, 1066-1071.

8 R. C. Zanardo, V. Brancaleone, E. Distrutti, S. Fiorucci, G. Cirino and J. L. Wallace, FASEB J., 2006, 20, 2118-2120.

9 D. R. Linden, Antioxid. Redox Signaling, 2014, 20, 818-830.

10 A. Papapetropoulos, A. Pyriochou, Z. Altaany, G. Yang, A. Marazioti, Z. Zhou, M. G. Jeschke, L. K. Branski, D. N. Herndon, R. Wang and C. Szabo, Proc. Natl. Acad. Sci. U. S. A., 2009, 106, 21972.

11 Y. H. Chen, W. Z. Yao, B. Geng, Y. L. Ding, M. Lu, M. W. Zhao and C. S. Tang, Chest, 2005, 128, 3205-3211.

12 K. Eto, T. Asada, K. Arima, T. Makifuchi and H. Kimura, Biochem. Biophys. Res. Commun., 2002, 293, 1485-1488.

13 P. Kamoun, M. C. Belardinelli, A. Chabli, K. Lallouchi and B. Chadefaux-Vekemans, Am. J. Med. Genet., Part A, 2003, 116, 310-311.

14 S. Fiorucci, E. Antonelli, A. Mencarelli, S. Orlandi, B. Renga, G. Rizzo, E. Distrutti, V. Shah and A. Morelli, Hepatology, 2005, 42, 539-548.

15 N. S. Lawrence, J. Davis, L. Jiang, T. G. J. Jones, S. N. Davies and R. G. Compton, Electroanalysis, 2000, 12, 1453-1460.

16 J. Radford-Knoery and G. A. Cutter, Anal. Chem., 1993, 65, 976-982.

17 J. Bae, M. G. Choi, J. Choi and S.-K. Chang, Dyes Pigm., 2013, 99, 748-752.

18 F. Yu, P. Li, P. Song, B. Wang, J. Zhao and K. Han, Chem. Commun., 2012, 48, 2852-2854.
19 A. R. Lippert, E. J. New and C. J. Chang, J. Am. Chem. Soc., 2011, 133, 10078-10080.

20 H. Peng, Y. Cheng, C. Dai, A. L. King, B. L. Predmore, D. J. Lefer and B. Wang, Angew. Chem., Int. Ed., 2011, 50, 9672-9675.

21 Y. Chen, C. Zhu, Z. Yang, J. Chen, Y. He, Y. Jiao, W. He, L. Qiu, J. Cen and Z. Guo, Angew. Chem., Int. Ed., 2013, 52, 1688-1691.

22 C. Liu, J. Pan, S. Li, Y. Zhao, L. Y. Wu, C. E. Berkman, A. R. Whorton and M. Xian, Angew. Chem., Int. Ed., 2011, 50, 10327-10329.

23 M. M. Richter, Chem. Rev., 2004, 104, 3003-3036.

24 W. Miao, Chem. Rev., 2008, 108, 2506-2553.

25 X. Yue, Z. Zhu, M. Zhang and Z. Ye, Anal. Chem., 2015, 87, 1839-1845.

26 P. McCord and A. J. Bard, J. Electroanal. Chem. Interfacial Electrochem., 1991, 318, 91-99.

27 D. Bruce, M. M. Richter and K. J. Brewer, Anal. Chem., 2002, 74, 3157-3159.

28 M. M. Richter and A. J. Bard, Anal. Chem., 1996, 68, 26412650.

29 M. M. Richter, J. D. Debad, D. R. Striplin, G. A. Crosby and A. J. Bard, Anal. Chem., 1996, 68, 4370-4376.

30 E. M. Gross, N. R. Armstrong and R. M. Wightman, J. Electrochem. Soc., 2002, 149, E137.

31 Y. You and W. Nam, Chem. Soc. Rev., 2012, 41, 7061-7084.

32 Y. Zhou, H. Gao, X. Wang and H. Qi, Inorg. Chem., 2015, 54, 1446-1453.

33 M.-J. Li, P. Jiao, M. Lin, W. He, G.-N. Chen and X. Chen, Analyst, 2011, 136, 205-210.

34 J. M. Fernandez-Hernandez, E. Longhi, R. Cysewski, F. Polo, H.-P. Josel and L. De Cola, Anal. Chem., 2016, 88, 4174-4178.

35 X. Cao, W. Lin, K. Zheng and L. He, Chem. Commun., 2012, 48, 10529-10531.

36 T. Liu, Z. Xu, D. R. Spring and J. Cui, Org. Lett., 2013, 15, 2310-2313.

37 Y. Liu and G. Feng, Org. Biomol. Chem., 2014, 12, 438-445.

38 J. I. Kim, I.-S. Shin, H. Kim and J.-K. Lee, J. Am. Chem. Soc., 2005, 127, 1614-1615.

39 R. Y. Lai and A. J. Bard, J. Phys. Chem. A, 2003, 107, 33353340 . 